\title{
System Dynamics Model of Supplier Function in ERP construction Project
}

\author{
Ruikang Liu ${ }^{1+}$ \\ ${ }^{1}$ Business School, Sichuan University, China
}

\begin{abstract}
ERP plays a huge role in the development of enterprises, but the implementation of ERP construction projects is usually affected by many factors, and the role of vendor is an important part. In this paper, we integrally consider the overall project and the role of vendor to explore the utility of efforts of vendor in different directions and the influencing factors for the effort of vendor. Based on the method of system dynamics, we conduct modeling and simulation, and analyze the role and influencing factors of vendor in ERP construction projects through the analysis of the simulation results.
\end{abstract}

Keywords: System dynamics, Enterprise resource planning, Vendor's effort

\section{Introduction}

Enterprise resource planning is a management information system based on information technology [1], which integrates information technology and advanced management ideas, and provides decision-making means for enterprise employees and decision makers with systematic management ideas. ERP is a complete enterprise management system, including procurement, production, finance and sales. In the context of big data, single module management system cannot meet the current needs [2] [3]. Therefore, the application of ERP system has become the top alternative for enterprise management. The system conducts business and production planning from a global perspective, and its core management idea is to achieve effective management of the entire supply chain. In the current information age, the construction of ERP is indispensable for enterprises to achieve efficient operation and lean production, and to develop from a small company to a certain scale of enterprises.

But at the same time, the implementation of ERP is based on data, which may be diverged from the management concept of the original management, causing the resentment and conflict of management and even employees [4]; On the other hand, building an ERP system with enterprise characteristics generally requires a large cost, and a suitable ERP project needs continuous discussion with vendors and consultants to continue. As LENOVO builds its own ERP system through continuous discussion with SAP and Deloitte, and it finally has achieved good results.

Therefore, it can be found that there are certain risks in the project of an enterprise building its own ERP [5] [6], and the vendor plays a huge role in the progress and risk control of the project. Therefore, we hope to study this through the system dynamics method. In the previous studies, the role of software vendor in ERP project construction was mostly studied from a static and qualitative perspective. Although Yong JIN et al. [7] discussed the role of vendors in ERP implementation projects through the system dynamics model, but when it comes to establishing the model, they simply attributed the efforts of vendors to the efforts of project tasks and the efforts of collaboration, and believed that the two had the effects of promoting the completion of project work and promoting trust establishment. However, they failed to effectively take the role of vendors, project progress and the impact of enterprises into account in the model, nor did they consider the deeper impact.

In our opinion, in the process of discussing an enterprise's ERP construction project, the role of vendor is not only influenced by vendor itself, but also influenced by the enterprise and the project, and ultimately affects the project schedule. For example, the ERP construction project will obviously be affected by the

Corresponding author. Tel.: +8615680913549 .

E-mail address: 1rklrk132@163.com. 
urgency of the enterprise to build an information system, which is the fundamental driving force of the enterprise to promote the project. On the other hand, the cost to be paid for the construction of ERP system will affect the operating conditions of enterprises. Considering the current situation that most enterprises employ professional managers, such choice will reduce the determination of the management to promote the construction of ERP system and hinder the role of vendor. Therefore, through the structure optimization and parameter optimization of the system dynamics model of vendor role in the previous ERP construction project, we hope to further explore this issue and study the influence of relevant parameters on the results.

\section{Modeling building}

\subsection{Modeling Ideas}

Based on the case study of ERP system construction by enterprises, we can find that the promotion of the project is the result of the joint action of enterprises, vendors and consulting companies. Enterprises have a clear understanding of their own needs, which promotes the implementation of informatization. However, the construction of ERP system will have a certain negative impact on the short-term business conditions of enterprises and affect the original operation mode of enterprises, so there are different attitudes to building systems within the enterprise. Vendors have a higher technical level and can solve various problems in the process of constructing ERP system according to their own experience. However, they lack in-depth understanding of the needs of the enterprise, and there are also some problems in the collaboration and communication between project members and enterprise employees. Consultancies are somewhere in between, relying on their experience and preparation to help projects move smoothly.

According to the above analysis, we can find that the main body of an ERP construction project is the enterprise and the vendor. Therefore, with a view to discussing the role of the vendor in the ERP construction project, it must be combined with the enterprise. Otherwise, simply considering the effort and direction of the software vendor, it is too idealistic or simplistic in terms of a simulation model. Therefore, we hope to discuss the role of vendor in ERP construction projects from more perspectives and in combination with the enterprise itself.

For an ERP construction project, the impact of many factors on project progress is obvious, such as the support of enterprises or the familiarity of employees, which will undoubtedly accelerate the progress of the project. However, in the case study, we have found some interesting problems. On the one hand, the demand for building an information system of enterprise will improve the enterprise's support for the project, and on the other hand, it will also put forward higher requirements for the project. The former will undoubtedly have a favorable impact on the project, while the latter is on the contrary. Under the combined effect of these two situations, what kind of impact will it have on an ERP project?

\subsection{Causal Loop Diagram}

Based on the above purpose, we consider the relevant factors of the model on the basis of the system dynamics method, and hold the view that the model should include the following main factors and other auxiliary variables.

(1) Project progress: The underlying indicators for evaluating the progress of a project and showing the completion of the ERP construction project. Quantitative processing and expression with functions of employees' support and change motivation of enterprise.

(2) The effort of vendor: Affected by the initial effort of vendor and the change motivation of enterprise, it indicates the help provided by vendor to complete the project. This variable means that the value of the parameter does not change during a simulation run.

(3) The effort of vendor on communication: Vendor's efforts in communication with enterprises, fluctuate between $0-1$ in ratio.

(4) The effort of vendor on pushing the project: Vendor's efforts in pushing the project progress, which is similar to the effort of vendor on communication.

(5) Education and training for enterprise: education and training activities for enterprises. The variable works as a constant in an experiment. 
(6) Employee's familiarity with the project: Based on the communication with vendor and education and training. Jointly decided by vendor's effort on communication and education and training for enterprise, and expressed as a function of the product of the two.

(7) The support of employers: Based on the demand for enterprise informatization and affected by the effort of vendor on pushing the project. Expressed as a function of the product of the two.

(8) The support of employees: employee's familiarity with the project and the support of employers both will strengthen employees' support. Taking into account the nature of the variable, it is expressed with functions including project progress, employees' familiarity with the project and the support of employers.

(9) Change motivation of enterprise: Enterprise needs for project changes.It is a constant.

(10) Demand for enterprise informatization: The requirement of enterprise informatization, which will change based on the requirement of enterprise modification.

In 2.3, there are more detailed explanations and expressions for variables and parameters.

Therefore, we can make a causal feedback model of this model, as shown in Figure 1.

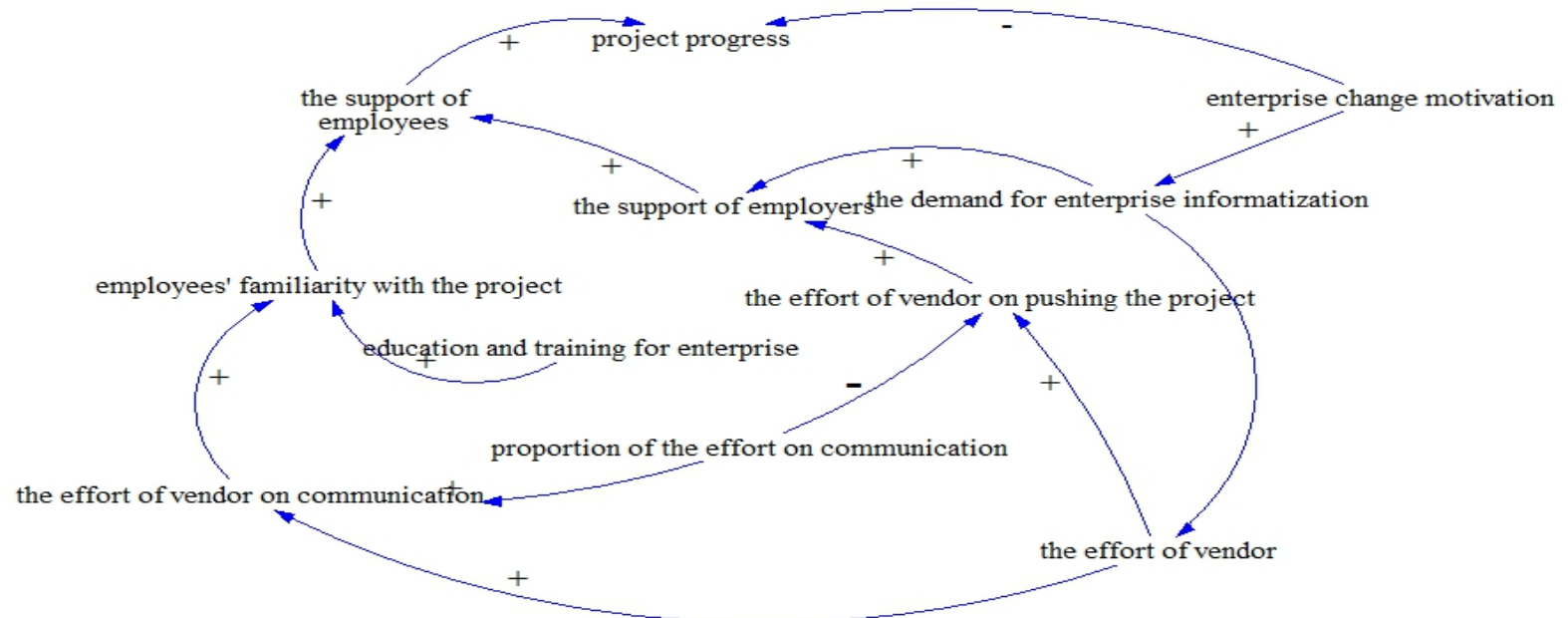

Fig 1: The causal feedback diagram of the model

The basic idea of the causal feedback diagram is that the effort of vendor is divided into two aspects: communication and project promotion. When the effort of vendor is constant, the sum of the two is constant, and when the effort of vendor increases, both will increase. Additionally, the effort of vendor is also restricted by the demand for enterprise. The greater an enterprise demands, the more dependent it has on vendor and the more efforts it makes by itself, which leads to the vendor to appropriately reduce its own efforts. Vendor's efforts in communication, education and training will increase employees' familiarity with the project, thus affecting their support for vendor. Vendor's efforts to promote a project will strengthen the support of the employers and affect the support of the employees. Employees' support will have a positive impact on the project process while the change of enterprise demand will have a negative impact. The demand for enterprise informatization is influenced by the change motivation of enterprise, and can influence the employers' support of vendor.

The theory of system dynamics demonstrates that, in the causal loop diagram, the positive feedback loop will play a magnifying role, while the negative feedback loop will stabilize the system, which also becomes a way to test the simulation effect of the system.

\subsection{System Flow Diagram}

In the process of constructing the stock flow diagram, it is necessary to further supplement the model, and take the types of various factors into consideration. In the flow diagram, we believe that the project process is the key to the measurement of the whole model, and it is also a direct reflection of the role of the other parameters. Employee support and enterprise change motivation are two factors that directly affect the project process. 


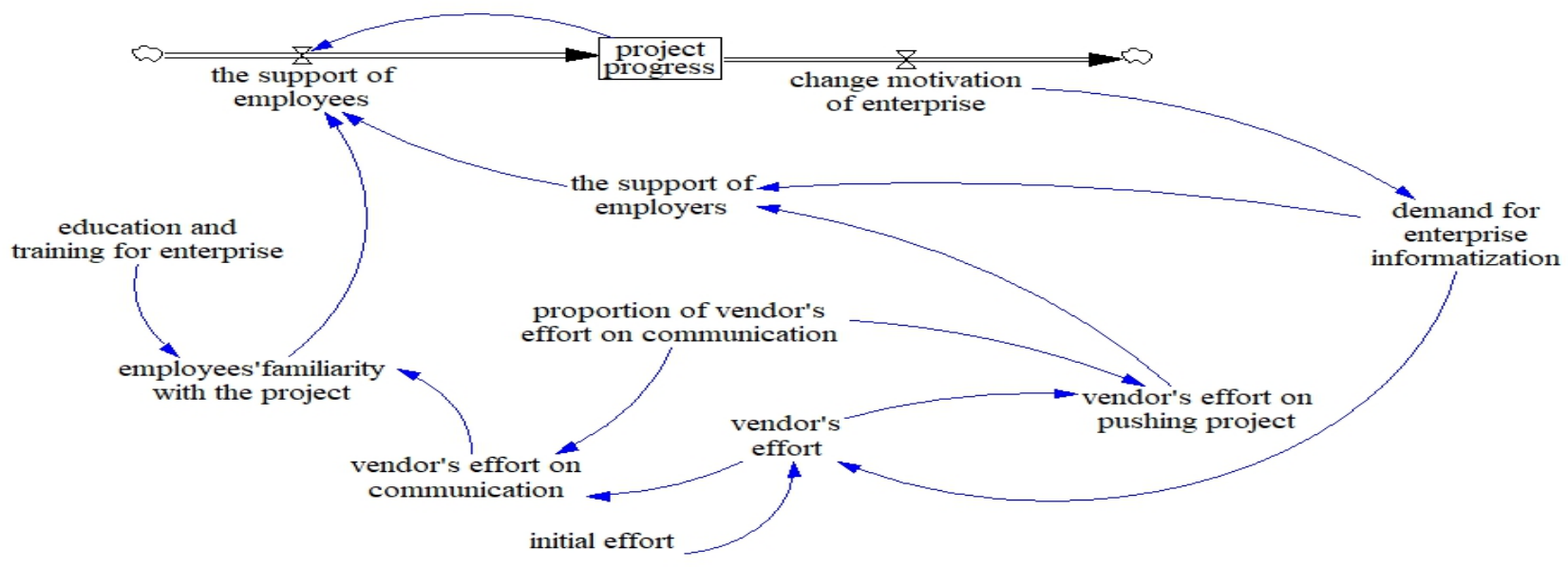

Fig 2: The stock flow diagram of the model

In this model, there are the following assumptions

(1) Excluding the personnel changes in the process of the project, and supposing those who share the same identity have the same influence on the project.

(2) Measuring the influence of each factor by the unit of day.

(3) Measuring the subjective factors in the model by relevant factors.

(4) Since the most factors in the model are difficult to be fully measured, the correlation is described by two kinds of relations, + and -, as well as some trend functions that can represent the relationship.

Based on the above assumptions, both the system dynamics stock flow diagram and the interrelationship are constructed. Some complicated relationships are explained in the following table:

Table 1: explanation of some parameters

\begin{tabular}{ll}
\hline \multicolumn{1}{c}{ Parameter } & \multicolumn{1}{c}{ Equation } \\
\hline Project progress & $\begin{array}{l}\text { Integ ( the support of employees-change motivation of enterprise, } \\
30)\end{array}$ \\
\hline The support of employees & $\begin{array}{l}\text { MAX }(0,(100 \text {-project progress }) / 1000) * 5 *(\text { employees' familiarity } \\
\text { with the project }+ \text { the support of employers })\end{array}$ \\
\hline $\begin{array}{l}\text { Employees' familiarity with the } \\
\text { project }\end{array}$ & $\begin{array}{l}\text { vendor's effort on communication*education and training for } \\
\text { enterprise }\end{array}$ \\
$\begin{array}{l}\text { Vendor's effort on } \\
\text { communication }\end{array}$ & vendor's effort*proportion of vendor's effort on communication \\
\hline $\begin{array}{l}\text { Vendor's effort on pushing } \\
\text { project }\end{array}$ & vendor's effort* $(1$-proportion of vendor's effort on communication $)$ \\
\hline $\begin{array}{l}\text { Vendor's effort } \\
\text { Demand for enterprise } \\
\text { informatization }\end{array}$ & initial effort- $0.1 *$ demand for enterprise informatization \\
\hline
\end{tabular}

\section{Model Testing and Result Analysis}

\subsection{The Influence of the Initial Effort of Vendor}

In the first case, considering that the change motivation of an enterprise is 0 , that means, the enterprise does not put forward more requirements for ERP projects. The initial effort of vendor is 1, the education and training provided by vendor is 0 , and the initial effort of vendor is increased to 2 , the project progress comparison curve is shown in the figure below. It can be found that although the initial efforts of vendor are doubled, the impact on the project progress is very limited. This is because although the initial efforts will affect the efforts of the vendor, the latter will also be affected by negative feedback caused by the progress of the project, thus making the general efforts of vendor tend to be stable. This is clearly consistent with the theory of system dynamics and also with the actual situation. The same is true for other relevant factors such as the support of employers. 

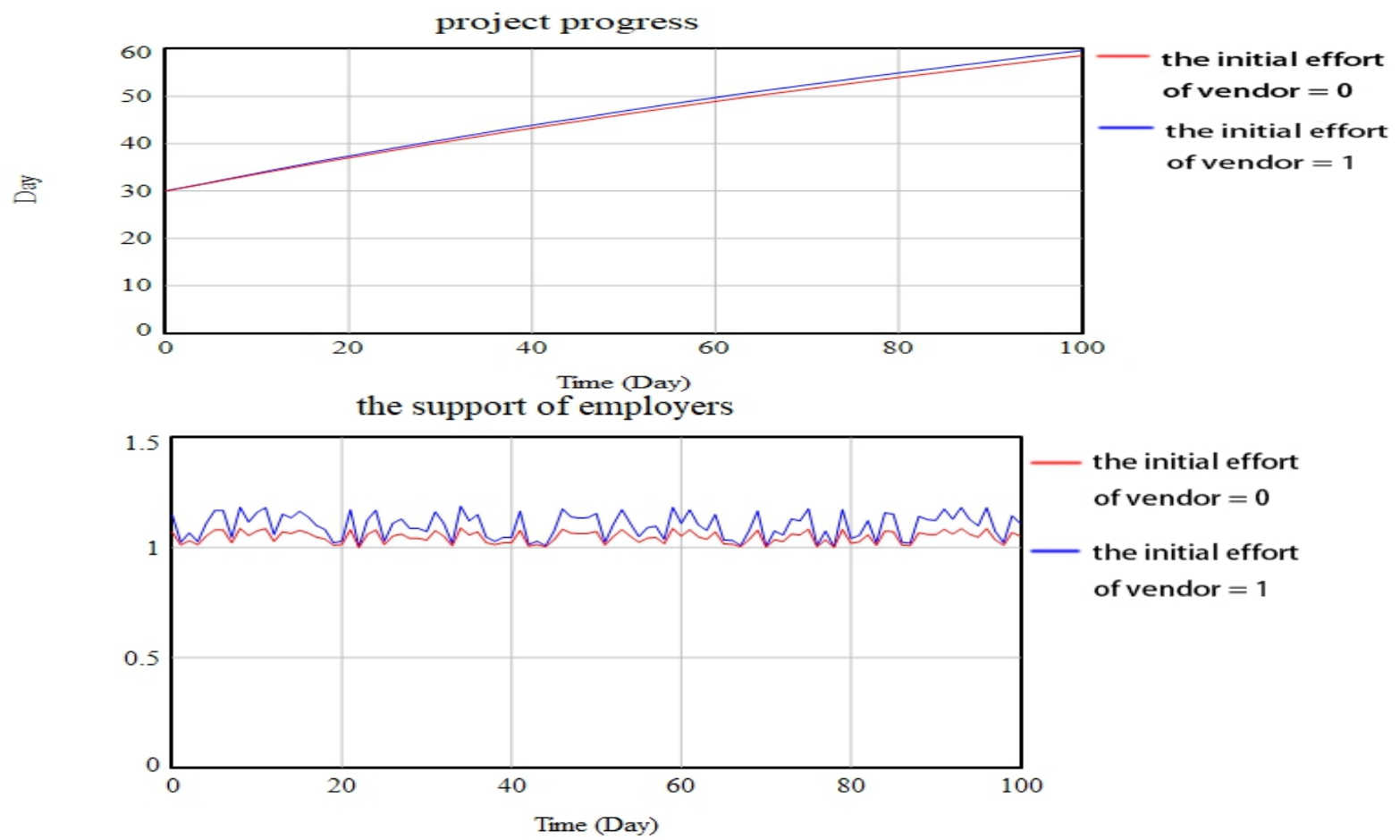

Fig 3: Impact of the initial effort of vendor on project progress and the support of employers.

\subsection{The Influence of Education and Training of Vendor}

In the second case, the education and training of software vendor is set as 1 , and the initial efforts of software vendor are 2 and 1. Combined with the simulation results of the system in the first case, it can be found that the project progresss is significantly changed compared with that in the case where vendor does not do education and training. From the perspective of employees' familiarity with the project, the initial efforts of vendors are likely to make employees more familiar with the project.

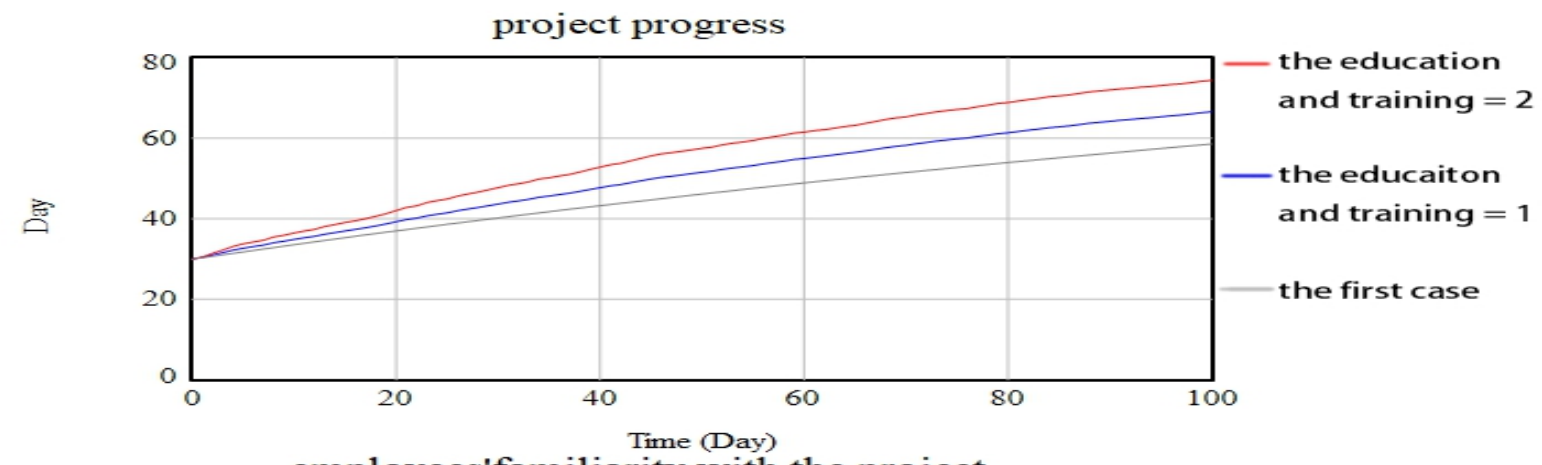

employees'familiarity with the project

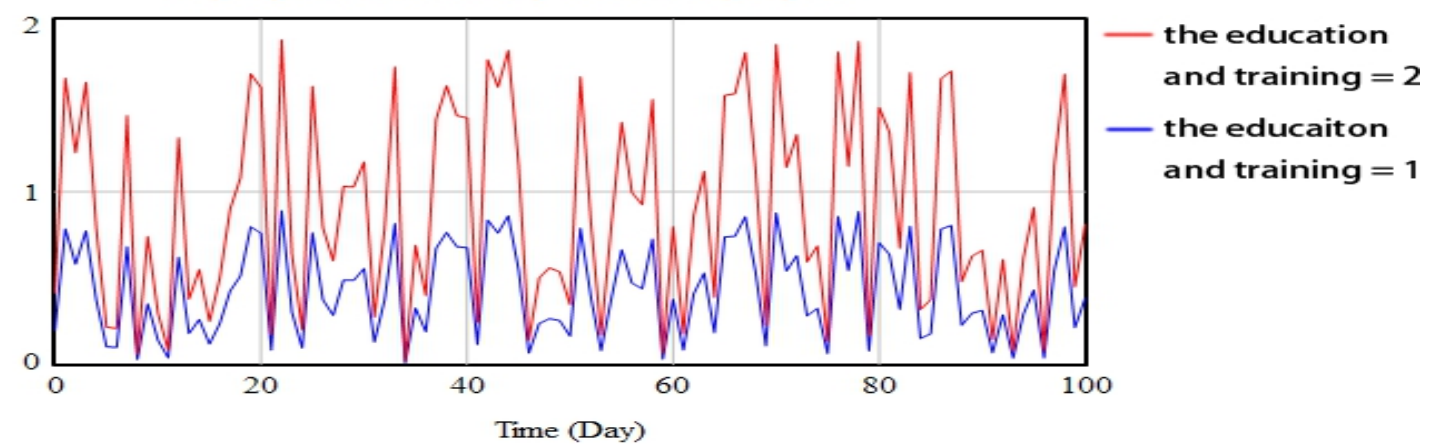

Fig 4: Impact of education and training on project progress and employee' s familiarity with the project.

\subsection{The Influence of the Distribution of the Effort of Vendor}

In the third case, given that the proportion of vendor's efforts in communication is constant 0.5 and 0.2 , it can be found that increased investment in communication will speed up the process of the project. If the two cases are considered in which the previous communication ratio follows a uniform distribution of 0 to 1 , we 
observe the comparison curve of project progress and employee project familiarity in the four cases. We can find that when the other parameters remain unchanged, the vendor' $\mathrm{s}$ effort to adopt 0 to 1 uniform distribution in communication is better than the adoption of fixed values, because the system has an automatic and stable effect. In the case that the vendor continuously changes the ratio of the two efforts, there is a delay and self-stabilization effect due to the system's response. For example, vendor's investment in communication reaches a large value in one day, and based on the previous conclusion, the project progress will be accelerated. Because the existence of the negative feedback tends to weaken its influence in the system, and its delay is fed back to the system later and the supplier ' $\mathrm{s}$ investment in communication obeys uniform distribution. After this day, vendor's investment in communication has a large probability of decrease, which, together with the previous decrease, reduces the influence and finally leads to this phenomenon.
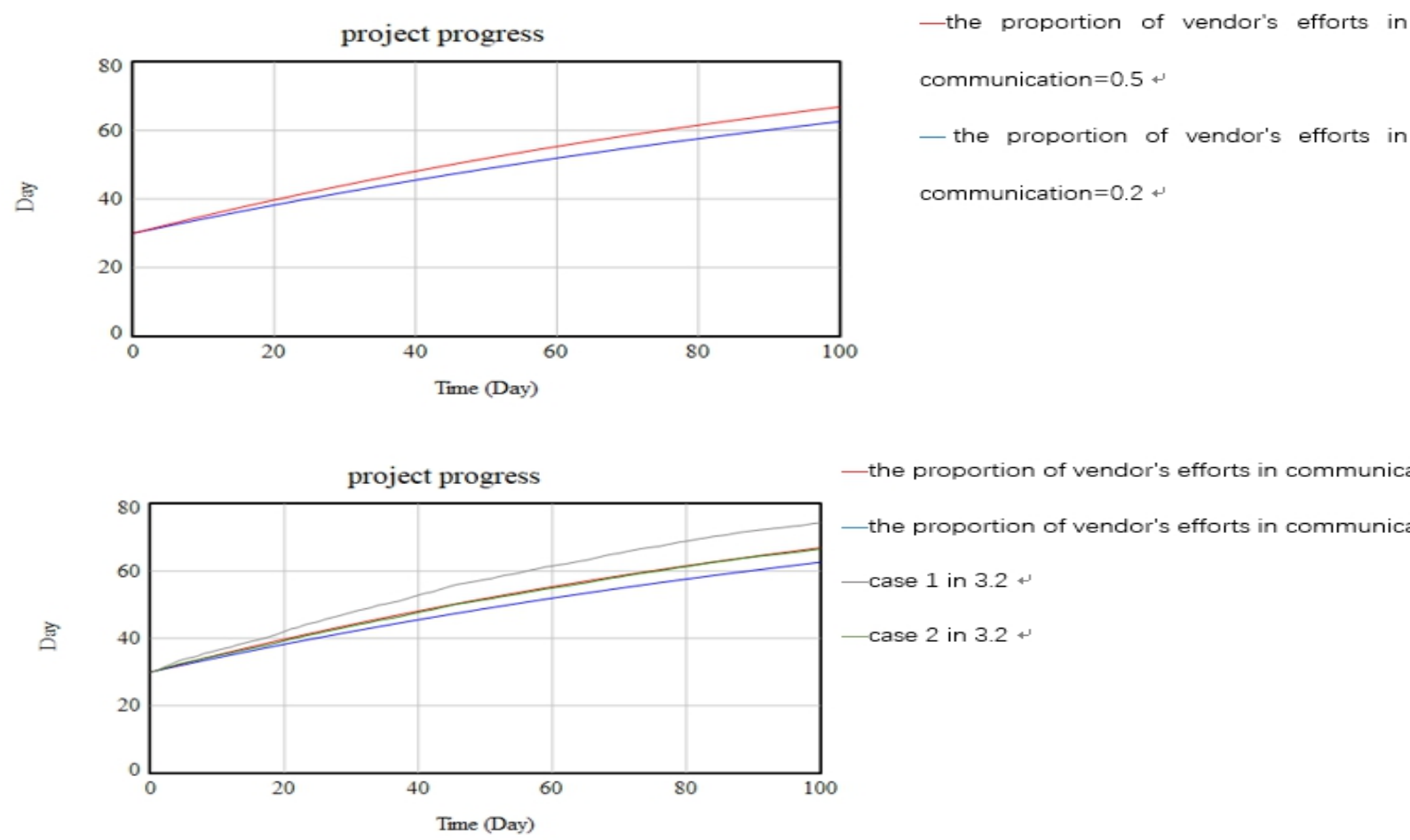

- the proportion of vendor's efforts in communication $=0.5$ the proportion of vendor's efforts in communication $=0.2$ - case 1 in 3.2 - case 2 in 3.2

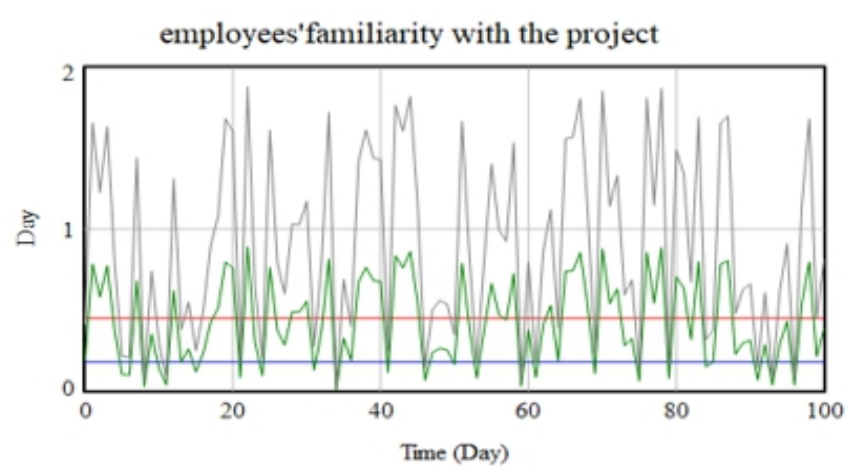

-the proportion of vendor's efforts in communication $=0.5$ -the proportion of vendor's efforts in communication $=0.2$ -case 1 in 3.2 -case 2 in 3.2

Fig 5: Impact of the distribution of effort of vendor on project progress.

\subsection{The Influence of Change Motivation of Enterprise}

In this case, we discuss a question raised in part 2.1, that is, how the increase in the change motivation of enterprise affects the system. Red line and blue line represent the situation of small change motivation and large change motivation. According to the simulation results, it can be found that the increase of change motivation of enterprise will undoubtedly improve the information needs of enterprises and the support of employers. However, due to the negative feedback of enterprise information needs on the efforts of software vendors, it will reduce the efforts of vendors, and then affect the links after the cycle. Although employee 
support is affected by two aspects, but according to the diagram, the increasing motivation of enterprise changes will still slow down the project progress.

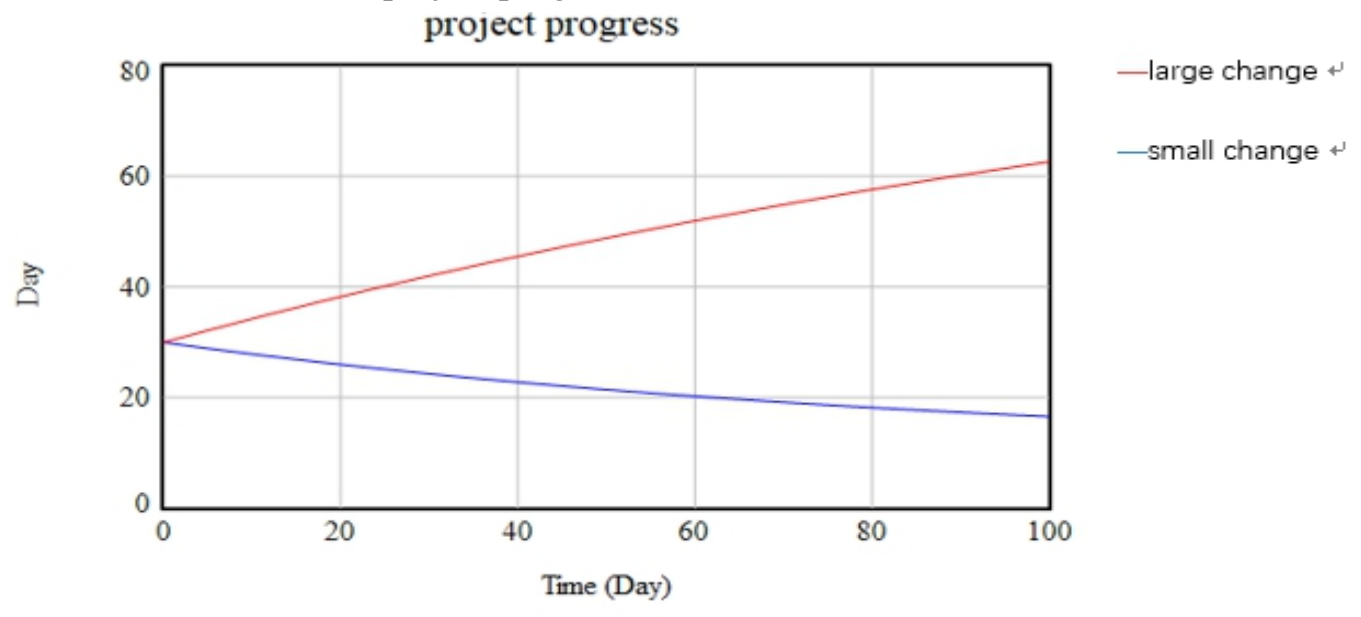

Fig. 6: Impact of the change motivation of enterprise on project progress.

\section{Conclusion}

\subsection{Conclusion}

The construction of ERP system is an important part of enterprise development, and software vendor is an important participant in the project. This paper explains the relevant factors that affect the utility of vendor and the construction of ERP projects from the perspective of vendor. This paper illustrates the model through the system dynamics method, constructs the causal feedback diagram and flow diagram of vendors and enterprises in the ERP construction project, and regards the project progress as the main evaluation index to explore the influence of the other changing factors.

\subsection{Limitation}

Since many parameters in this model are difficult to quantify, it can only reflect the general trend and mutual relations, and it is difficult to accurately represent various problems in ERP construction projects, which needs further research and discussion.

\section{References}

[1] Zheng, Wei. Cost Control of SMEs in ERP Environment [J]. Accounting of Chinese Township Enterprises, 2021(04): :96-97.

[2] Jiang, Shaozhen. Application of ERP System in Financial Management [J]. China Collective Economy, 2021(09): 137-138.

[3] Xi, Wenzhi. Research on the effective application of ERP system in enterprise information construction [J]. Energy Science and Technology, 2020,18(11):16-18.

[4] Xiao, Linyu. The Influence of ERP on Human Resource Management [J]. Energy Science and Technology, 2020,18(11): 49-51.

[5] Lian, Deguan. Enterprise internal control risk and prevention under ERP system [J]. China Small \& Medium Enterprises, 2020(12): :90-91.

[6] Shen, Qiqiong. Enterprise Financial Risk Control Management in ERP Environment [J]. Taxpaying, 2021,15(02): :151-152.

[7] Jin, Yong, Sun, Jie, Qi, Ruikun. System Dynamics Analysis of External Risk in ERP Implementation [J]. China Collective Economy, 2011(12):89-90. 